\title{
Qualitative Study of Practices and Challenges of Stepping Down Asthma Medication in Primary Care Across the UK
}

This article was published in the following Dove Press journal: Journal of Asthma and Allergy

\author{
Chloe I Bloom (D) \\ Helen Ramsey ${ }^{2}$ \\ Marsha Alter $\mathbb{D D}^{3}$ \\ Shivali Lakhani ${ }^{3}$ \\ Ernie Wong ${ }^{4}$ \\ Katharine Hickman ${ }^{5}$ \\ Sarah L Elkin ${ }^{4}$ \\ Azeem Majeed ${ }^{6, *}$ \\ Austen El-Osta $\mathbb{1}^{6,7}, *$
}

\begin{abstract}
'Airways Disease Section, National Heart and Lung Institute, Imperial College London, London, UK; ${ }^{2}$ Kent and Medway CCG, Swanscombe and Bean Partnership, Swanscombe Kent, UK; ${ }^{3}$ Middlesex Pharmaceutical Group of LPCs \& Community Pharmacy Research Champion NIHR NWL CRN, London, UK; ${ }^{4}$ Department of Respiratory Medicine, Imperial College Healthcare Trust, London, UK; ${ }^{5}$ West Yorkshire \& Harrogate Health and Care Partnership, Low Moor Medical Practice, West Yorkshire, UK; ${ }^{6}$ Department of Primary Care \& Public Health School of Public Health, Imperial College London, London, UK; ${ }^{7}$ Self-Care Academic Research Unit (SCARU) Department of Primary Care \& Public Health School of Public Health, Imperial College London, London, UK
\end{abstract}

*These authors report no conflicts of interest in this work

Correspondence: Chloe I Bloom Airways Disease Section, National Heart and Lung Institute, Imperial College London, London, UK

Email chloe.bloom06@imperial.ac.uk
Background: Guidelines recommend that asthma treatment should be stepped down to the minimally effective dose that achieves symptom control to prevent medication side effects and reduce unnecessary costs. Little is known about the practice of stepping down and the challenges in primary care, where most asthma patients are managed.

Objective: To explore views, experiences, barriers and ideas, of doctors, nurses and pharmacists working in primary care, related to step down of asthma medication.

Methods: Primary care practitioners from across the UK participated in a survey and/or semi-structured interview. Questions explored four main areas: how asthma medication is reviewed, views on asthma guidelines, perceived barriers faced by healthcare workers and facilitators of stepping down. Qualitative content analysis enabled data coding of interview transcripts to identify major themes.

Results: A total of 274 participants responded to the survey, 29 participated in an interview (12 doctors, 9 nurses, and 8 pharmacists), working in GP practices from across the UK. Nearly half of the survey participants infrequently step down asthma medication (doctors $=42.7 \%$, nurses $=46.3 \%$ ). Four major themes related to barriers to stepping down were (i) lack of awareness of the need to step down, (ii) inertia to step down, driven by low confidence in ability, fear of consequences, and concern for who is responsible for stepping down, (iii) self-efficacy of ability to step down, influenced by lack of clear, applied guidance and limited training, and (iv) feasibility of step down, driven by a lack of systematic acceptance of stepping down and time. Strategies proposed to reduce overtreatment included education and training, improved gathering of evidence and guidance, and integrating step down into routine asthma care.

Conclusion: Failure to implement this guideline recommendation into everyday asthma management is influenced by several contributing factors. Future directions should include addressing evidence gaps, implementing clear and practical guidance, integration of stepdown assessment into the asthma review, and education of professionals and patients.

Keywords: stepping down, asthma, qualitative, perceptions, primary care

\section{Introduction}

Around $7 \%$ of UK adults have active asthma, with an increasing proportion receiving preventer medication. ${ }^{1}$ The predominant UK asthma guidelines, the British Thoracic Society/Scottish Intercollegiate Guidelines Network (BTS/SIGN), the National Institute for Health and Care Excellence (NICE), and the international Global Initiative for Asthma (GINA) report, recommend a stepwise approach to pharmacological management. ${ }^{2-4}$ For each progressive step, medication can be increased. 
Correspondingly, once asthma control is maintained, medication step down should be considered to achieve the minimally effective dose.

There are several consequences of long-term overtreatment of asthma. Firstly, patients may be at increased risk of side-effects, including cataracts, osteoporosis and diabetes $^{5}$. Secondly, inhalers are a large cost-burden to the NHS, contributing around $13 \%$ of the primary care prescribing budget. ${ }^{6}$ Lastly, medication burden may contribute towards poor adherence. ${ }^{7}$

In the UK, there has been an increase in the proportion receiving higher level medication (medium or high dose inhaled corticosteroids, ICS). ${ }^{1}$ Of those prescribed a medium/high dose combination inhaler as their first ever preventer, $70 \%$ remained on the same inhaler for several years. ${ }^{1}$

However, the literature on barriers to stepping down asthma medication is sparse. As nearly all (96\%) of asthma patients are managed in primary care, ${ }^{8}$ we sought to understand the perceptions of practitioners managing asthma patients in that setting.

\section{Methods}

\section{Design}

The study adopted a qualitative methodology, using a questionnaire and semi-structured interviews from a convenience sample of doctors, nurses and pharmacists (community and GP) from primary care across the UK. For the interviews, we selected a sub-sample to incorporate a mix of clinical roles and specialist interest in asthma.

\section{Ethics}

The study was reviewed by Imperial College Research Ethics Committee who approved the study (ICREC reference 20IC6026). Personal information for the interview participants was stored at Imperial College London in a password-protected site by the investigator. No incentives were offered to volunteer.

\section{Participant Recruitment}

Primary care practitioners were invited to take part in the study through local primary care networks, personal contacts, professional social media networks (local groups, and nationwide - Physician Mums Group UK) and the Primary Care Respiratory Society. In the UK, patients with asthma may be managed by their GP, practice nurse or practice pharmacist. There is considerable variability across GP practices in who manages asthma and who is mainly responsible for their care - depending in part on the experience level of the professional, their interest in asthma, any additional training/qualifications they may have and the size of the practice. In general, a practice nurse, or often a practice pharmacist, will carry out all routine reviews; it is during a review that step down is most likely to be considered. Community pharmacists that work only in pharmacies are also sometimes qualified to prescribe and may have undertaken training specifically in asthma management, although this is much less common.

A range of interview participants were selected based on their years of experience and interest in asthma.

All study participants provided informed consent, including consent to the publication of their anonymized responses; participants were told the length of time of the survey and interview, where the data was stored and for how long, who the investigator was and the purpose of the study. Personal information was stored only for participants volunteering to do an interview, this information was stored in password-protected site by the investigator. Survey and interviews were completed between JuneJuly 2020.

\section{Data Collection}

For practitioners working in a GP practice, a thirteenquestion (one page) open eSurvey using Qualtrics survey tool was used to assess the frequency of stepping down, medication reviews, and reasons for and against stepping down. Community pharmacists answered a shorter sixitem (one page) version of the survey. The questionnaires and interviews were first discussed with knowledgeable key informants (face validity) before drawing up a question guide which was piloted, developed, modified and informed by a review of the literature ${ }^{9-12}$ (Supplementary Table 1). Respondents were able to review and change their answers. Duplicated entries were avoided by preventing users with the same IP address access to the survey twice.

Interviews explored views and experiences in more depth (Supplementary Table 2). Specifically, our objectives were to:

(a) Determine how asthma medication is reviewed

(b) Identify views on asthma guidelines

(c) Explore the perceived barriers faced by healthcare workers

(d) Identify drivers and facilitators of stepping down 
One-to-one interviews were carried out by CIB (a female respiratory epidemiologist at Imperial College London and honorary respiratory consultant) remotely through video or telephone. Interviews were digitally recorded and transcribed; transcripts were not repeated or returned to the participants. Participants were unknown to the interviewer prior to the interview. Field notes were used to record relevant contextual issues.

\section{Data Analysis}

All surveys were completed and analysed. Survey responses were summarised using frequencies and percentages. Interviews were analysed according to the principles of interpretive thematic analysis and facilitated using QDA Miner (University of Groningen). Initially, each transcript was coded using a process of open coding by CIB in discussion with AEO, followed by the development and clustering of themes in an interpretive process. The basic codes were elaborated into a framework that was continuously refined to reflect all the interviews (Supplementary Table 3). The Checklist for Reporting Results of Internet E-Surveys (CHERRIES) and Consolidated Criteria for Reporting Qualitative Research (COREQ) were used to guide reporting.

\section{Results}

\section{Study Participants: Survey}

There were 274 survey participants from 136 geographically diverse clinical commission groups (CCGs) (Supplementary Table 4) and 10 community pharmacies; comprising 207 doctors (85.8\%), 34 nurses (12.5\%) and 33 pharmacists (11.7\%). Participants were spread across a range of ages: $20-29$ years $=2.6 \%, 30-39$ years $=48.0 \%$, $40-49$ years $=31.0 \%, 50-59$ years $=12.6 \%, \geq 60$ years $=5.9 \%$, and included 51 males and 219 females.

\section{GP Practice Survey Findings}

Most participants "infrequently" stepped down medication (doctors $=42.7 \%$, nurses $=46.3 \%$ ); practice pharmacists most common response was "sometimes" (Table 1). Just over half of doctors, and around one-third of nurses, did not feel confident to step down (doctors no $=56.8 \%$, nurses no $=36.6 \%$ ); all the practice pharmacists felt confident. Most of the participants reported being aware of asthma guidelines recommending stepping down (doctors $=68.7 \%$, nurses $=87.8 \%$ and practice pharmacists $=100 \%$ ).

The two most selected reasons to step down were "to reduce medication burden" (67.8\%), and "guidelines recommend that I should consider stepping down" (46.9\%) (Table 2). The two most selected barriers were "patients don't want to" (37.0\%) and "I don't know who to step down" (30.0\%) (Table 2). Over one-third "infrequently" or "never" review asthma medication when seeing an asthma patient (Table 3). Reviews usually occurred during ad hoc consultations for doctors $(61.8 \%)$ but annual review for nurses $(82.9 \%)$.

\section{Community Pharmacy Survey Findings}

Over half of community pharmacists "never" or "infrequently" discussed stepping down (Table 4). In contrast, over two-thirds "sometimes" or "often" discussed stepping up (Table 4). The two most selected reasons to discuss step down were "to reduce side effects" (44.4\%) and "patients ask to step down" (40.7\%) (Table 5). The two most selected reasons not to discuss step down were "don't have patient records" (40.7\%) and "not aware I should be" (22.2\%) (Table 5).

\section{Study Participants: Interview}

Twenty-nine participants consented to have an interview: 12 doctors, 9 nurses and 8 pharmacists (Table 6). Nearly one-third of participants $(n=9)$ had specialist training in asthma, and median of 15 years (range 1-35 years) of experience working in GP practices. Interviews lasted between 25-35 minutes.

Four overarching themes were generated from the thematic analysis: approach to the pharmacological management of asthma, value of asthma guidelines, challenges of

Table I How Frequently of Stepping Down Asthma Patients

\begin{tabular}{|l|l|l|l|l|l|l|l|l|}
\hline \multirow{2}{*}{} & \multicolumn{2}{|l|}{ Doctors (n=234) } & \multicolumn{2}{l|}{ Nurses (n=34) } & \multicolumn{2}{l|}{ Practice Pharmacists (n=6) } & \multicolumn{2}{l|}{ Total (n=273) } \\
\cline { 2 - 9 } & $\mathbf{N}$ & \% & N & \% & N & $\%$ & N & $\%$ \\
\hline Never & 36 & 17.2 & 4 & 12.2 & 0 & 0.0 & 44 & 16.1 \\
Infrequently & 88 & 42.7 & 16 & 46.3 & 1 & 20.0 & 4 & 117 \\
Sometimes & 54 & 26.0 & 9 & 26.8 & 4 & 60.0 & 73 & 26.7 \\
Often & 29 & 14.1 & 5 & 14.6 & 1 & 20.0 & 39 & 14.3 \\
\hline
\end{tabular}


Table 2 Health Practitioners at GP Practice, Response to Questions Regarding Reasons for and Against Stepping Down

\begin{tabular}{|l|l|l|}
\hline Reason for Stepping Down & N & $\%$ \\
\hline Reduced medication burden & 185 & $67.8 \%$ \\
Guidelines advise that we should & 128 & $46.9 \%$ \\
Guidelines advise that we should & 128 & $46.9 \%$ \\
Reduce side effects & 113 & $41.4 \%$ \\
Patients ask me about reducing it & 93 & $34.1 \%$ \\
Reduce NHS costs & 61 & $22.2 \%$ \\
Other & 13 & $4.8 \%$ \\
\hline Reason Do Not Step Down & & \\
Patients do not want to & 101 & $37.0 \%$ \\
Do not know who to step down & 82 & $30.0 \%$ \\
Do not know how to step down & 59 & $21.6 \%$ \\
Not aware I should be & 33 & $12.1 \%$ \\
No point as the patient will step back up & 29 & $10.6 \%$ \\
Not my role (specialist's role) & 20 & $7.3 \%$ \\
\hline
\end{tabular}

stepping down medication and suggestions of future approaches. From these major themes, four main themes were identified as the barriers of stepping down: awareness, inertia, self-efficacy, and feasibility.

\section{Approach to the Pharmacological Management of Asthma}

Asthma reviews are usually carried out by nurses, sometimes by doctors or practice pharmacists and occasionally healthcare assistants.

I do all the reviews in my practice. As I am an independent prescriber, I have been given a lot of autonomy. Nurse 1. (specialist)

Nurses do data collection from the 3 RCP questions and peak flow readings but don't make decisions. Doctor 11

I work in four GP practices and the reviews are often done by the most junior nurse or healthcare assistant and are just a tick box exercise. Pharmacist 3

Most participants used a template or scoring system to assess asthma control.
Table 4 Frequency of Community Pharmacists Discussing Stepping Up and Stepping Down with Patients

\begin{tabular}{|l|l|l|}
\hline Discuss Stepping Down & N & $\%$ \\
\hline Never & 8 & 29.6 \\
Infrequently & 9 & 33.3 \\
Sometimes & 8 & 29.6 \\
Often & 2 & 7.4 \\
\hline Discuss Stepping Up & $\mathbf{N}$ & $\%$ \\
Never & $\mathrm{I}$ & 3.7 \\
Infrequently & 4 & 14.8 \\
Sometimes & 18 & 66.7 \\
Often & 4 & 14.8 \\
\hline
\end{tabular}

In our practice the nurses use a template but usually I just ask the patient. Doctor 9

All participants consider increasing asthma medication if there is worsening of symptoms, increase use of their reliever or deteriorating peak flow.

So, if they are symptomatic and using preventers, after checking they are compliant and using the inhalers properly, I would then go up in a step. I think I'm fairly happy to do it but I do have to keep looking at the guidelines.

Doctor 4

Apart from two participants, the rest were increasing asthma medication far more commonly than decreasing it.

I decrease much less, probably about ratio 10:1 as usually I only see them if problems. Nurse 3

Two participants, with specialist training, were much more likely to decrease asthma medication.

I decrease medication all the time. Patients are often sent to me on high dose Relvar or Seretide. Doctor 12

\section{Value of Asthma Guidelines}

All participants use asthma guidelines (most commonly BTS/SIGN). Participants were mostly content with the

Table 3 Frequency of Review of Asthma Medication

\begin{tabular}{|l|l|l|l|l|l|l|l|l|}
\hline & \multicolumn{2}{|l|}{ Doctors (n=234) } & \multicolumn{2}{l|}{ Nurses (n=34) } & \multicolumn{2}{l|}{ Practice Pharmacists (n=6) } & \multicolumn{2}{l|}{ Total (n=273) } \\
\cline { 2 - 9 } & $\mathbf{N}$ & $\%$ & $\mathbf{N}$ & $\%$ & $\mathbf{N}$ & N & N & $\%$ \\
\hline Never & 10 & $4.4 \%$ & 0 & $0.0 \%$ & 0 & $0.0 \%$ & 10 & $3.7 \%$ \\
Infrequently & 76 & $32.6 \%$ & 0 & $0.0 \%$ & 1 & $15.0 \%$ & 80 & $29.4 \%$ \\
Sometimes & 111 & $47.6 \%$ & 14 & $40.0 \%$ & 1 & $15.0 \%$ & 116 & $42.7 \%$ \\
Often & 36 & $15.4 \%$ & 20 & $60.0 \%$ & 4 & $70.0 \%$ & 66 & $24.3 \%$ \\
\hline
\end{tabular}


Table 5 Response to Question Regarding Reason to Discuss, or Not Discuss, Stepping Down Asthma Medication with Patients

\begin{tabular}{|l|l|l|}
\hline Reason Would Discuss Stepping Down & N & $\%$ \\
\hline Reduce side effects & 12 & $44.4 \%$ \\
Patients ask me about reducing it & II & $40.7 \%$ \\
Guidelines advise that we should & 9 & $33.3 \%$ \\
Reduced medication burden & 8 & $29.6 \%$ \\
Reduce NHS costs & 6 & $22.2 \%$ \\
Other & 3 & $11.1 \%$ \\
\hline Reason Did Not Discuss Stepping Down & 0 & \\
Not have patient records to be able to & II & $40.7 \%$ \\
Not aware I should be & 6 & $22.2 \%$ \\
No time & 5 & $18.5 \%$ \\
Patients do not want to & 4 & $14.8 \%$ \\
Not my role & 3 & $11.1 \%$ \\
\hline
\end{tabular}

guidelines; main issues were having two UK guidelines and the use of acronyms.

NICE and BTS are on two different pages. I use both and flit between two so use them as a resource rather than stick to them rigidly. Nurse 4

I know what a LABA is in the guidelines, but I don't know which inhaler it is in. Doctor 2

25 of the 29 interview participants responded in the survey that they were aware of step-down guidelines, but in the interview, only 3 participants had ever seen step-down guidance.

I've not seen a section on stepping down, but guidelines don't help me when I'm stepping patients down. Pharmacist 7

The guidelines are very helpful but I'm not aware where stepping down is. Nurse 9

The guidelines are not as explicit for decreasing medication, fairly vague. It is a more patient led approach. Doctor 9

There was a varied response when asking how participants step down. An example of a patient using two puffs twice a day of a medium dose combination inhaler was proposed.

I would reduce it by 3 puffs a day and give them a peak flow meter to monitor themselves. I review them every 3 to 6 months. Nurse 5

I would half the number of puffs they take. Doctor 12

If they had not used their reliever for a year, felt well and happy to trial it and given advice, I would prescribe them
Table 6 Characteristics of Interviewed Participants

\begin{tabular}{|c|c|}
\hline & $\mathbf{N}$ \\
\hline \multicolumn{2}{|l|}{ Role } \\
\hline GP & 12 \\
\hline Nurse & 9 \\
\hline Practice pharmacist & 8 \\
\hline \multicolumn{2}{|l|}{ Specialist Training } \\
\hline Doctor & 2 \\
\hline Nurse & 6 \\
\hline Pharmacist & 2 \\
\hline \multicolumn{2}{|l|}{ Gender } \\
\hline Male & 8 \\
\hline Female & 21 \\
\hline \multicolumn{2}{|l|}{ Age } \\
\hline $20-29$ & 2 \\
\hline $30-39$ & 8 \\
\hline $40-49$ & 8 \\
\hline $50-59$ & 6 \\
\hline $60+$ & 5 \\
\hline \multirow[t]{21}{*}{ CCGs } & \\
\hline & Bradford and Leeds \\
\hline & Brent \\
\hline & Bromley \\
\hline & Buckinghamshire \\
\hline & Camden \\
\hline & Central London \\
\hline & Dartford, Gravesham and Swanley \\
\hline & Doncaster \\
\hline & Ealing \\
\hline & Harrow \\
\hline & Herefordshire \\
\hline & Kent and Medway \\
\hline & Norfolk \\
\hline & North Central London \\
\hline & Sandwell and West Birmingham \\
\hline & Somerset \\
\hline & Tower Hamlets \\
\hline & Vale Royal \\
\hline & Wakefield \\
\hline & West London \\
\hline
\end{tabular}

a combination inhaler with half the steroid dose and use twice day. Nurse 4

If they had been stable for at least 3 months I would use their own experience and leave it up to them to decrease it. Nurse 1

Participants that did step down were asked at which time point they consider asthma to be stable enough to step down. Only two nurses based this on the guidelines (after 3 months of stability). 
Whenever I feel they are stable enough. Nurse 3

I think about it after they have been stable for 3 months, but I don't get to see them that often. Nurse 1

Participants were asked if they used SMART/MART (maintenance and reliever therapy regimens). Four of the 12 doctors (33\%) reported prescribing it, but 2 used it incorrectly. Six of the 8 pharmacists were familiar with SMART/MART. All 9 nurses used it, but those without specialist training, used it incorrectly or rarely.

I don't use it except if patients are aware, but most are not. Pharmacist 2

SMART rings a bell but I can't remember what it is. Doctor 7

I do use SMART in about $20 \%$ of my patients but people keep using their reliever too as they are so reliant on it its challenging to have that conversation. Nurse 2

I know about it, but I don't use it much. Nurse 1

\section{Barriers to Stepping Down Medication}

Participants suggested several barriers, these fell into four themes: poor awareness, inertia, lack of self-efficacy and feasibility.

There was a lack of awareness of the need to step down.

Patients do it without healthcare professionals if they are fairly aware, but they probably just stop rather than gradually decrease. Doctor 5

If I knew there were long term side effects from high dose inhaled steroids, I would reduce their medication if I had more awareness of the level of risk. Doctor 6

Inertia allowed participants to continue the same dose even if they thought they should step down. This was usually driven by a fear and concerns about who was responsible for step down.

If asthma is controlled, I would leave it. I wouldn't want to worry about a flare up but I am conscious of the long-term effects from steroids. I know we have room for improvement in our practice. Doctor 4.

They have to go up to control symptoms and then once controlled don't want to go down again as may have flare again later on. I appreciate though that the lower treatment the better. Doctor 10
If a doctor has started the patient on an inhaler with a high dose, I don't want to change that. Nurse 3

I don't want to risk it not working and they will lose faith in the nurse .... especially if they are younger, newly qualified they are less likely to do it. Doctor 9

The third theme, self-efficacy, reflects participants' ability, or inability, to step down medication. Contributing factors were lack of knowledge and skills, compounded by lack of guidance.

Guidance is not inherently clear. There is a ladder to step up but I'm not clear how I step them down. Doctor 3

Guidelines are very confusing about stepping down. Even the diagram goes upwards. Nurse 2

I wouldn't know how to step them down, should I reduce the inhaler dosage? I do know I should do it by steps, but I don't know where it is in the guidelines. Doctor 2

The last theme, feasibility, related to lack of time and lack of systematic acceptance of stepping down.

I have no time to do it as need time to educate them. Pharmacist 1

If they are not causing us trouble as patients, we don't have time to see them. Doctor 8

Mostly GPs are reactive to patients so respond to that. We're not good at being proactive. Doctor 1

\section{Facilitators of Stepping Down}

Facilitators included patient education and reassurance.

The fear is by the healthcare professional who don't want to destabilise the patient. But patients are usually happy to reduce once I educate them. Pharmacist 5

Patients are receptive because I have explained it to them, so they understand. Nurse 5

I talk to them about risk factors and trial bringing it down. Patients can be nervous, but I reassure them that if control slips just put them back on their high dose. Doctor 12

\section{Suggestions of Future Approaches}

Suggestions were focussed around incentives, education and training for the patients and healthcare workers, trying to incorporate stepping down into routine care and clear guidance. 
An incentive scheme for practices to change if new guidance came out would help. Doctor 1

I find it only works if I educate the patients. So, the most important thing is to get staff trained. Nurse 5

It would be a good idea to tell patients to think about in the future, but I don't do that at the moment. Nurse 3

Asking 'have you considered stepping down' in a template would help nurses in the reviews. Doctor 10

If it was built into the process it would happen more often. Pharmacist 4

There are areas in our practice where we deprescribe and so recall patients for that, like coming off statins and aspirin in the elderly. The same could happen for asthma. Doctor 8

Need a step-down plan similar to step-up and a leaflet for the patients similar to the asthma plan, so they can have reassurance and the onus is with them. Pharmacist 7

There is such a strong warning about asthma deaths so need to identify the subpopulation that can be safely stepped down and put that in a guideline. Doctor 6

\section{Use of Biomarkers and/or Pragmatic Trial}

Participants were specifically asked to comment on two potential methods that have been proposed to aid stepping down: fractional exhaled nitric oxide (FENO) and a pragmatic (real-life routine conditions) randomised controlled trial stepping down patients in primary care.

No participants had routine access to FENO. By comparison, all participants felt pragmatic evidence from a primary care setting would be beneficial.

Definitely help to have that evidence and a clear idea of when and who to do it for. Doctor 5

It would be very helpful and reassuring if the results show patient's asthma control stays the same. Brilliant idea to do it in GP setting. Doctor 6

\section{Discussion}

We explored the experiences and perspectives of primary care practitioners in relation to stepping down asthma medication. Doctors, nurses and pharmacists all managed patient's asthma medication but each from a different standpoint. Extant barriers to stepping down were categorised into four main themes: (1) lack of awareness, (2) inertia, (3) low self-efficacy and feasibility. Proposed approaches to reduce overtreatment included education and training, improved guidance and evidence gathering, and integrating step down into routine care.

Although tapering medication is a safe choice for many patients, most study participants reported infrequently stepping down medication as recommended in the guidelines. This was influenced by a variety of factors including attitudinal and practical barriers for practitioners, patients and systems. From a systems' perspective, there is little incentive to step down. In contrast, stepping up for worsening control is common, as patient's actively seek healthcare advice and practitioners regularly assess that need. Some participants exhibited a lack of awareness around the necessity to reach a minimally effective dose, whilst several doctors considered it as a proactive practice that they were not obliged to undertake or prioritise in routine general practice. Others perceived it as something patients should initiate themselves, without support. The belief that an asthma review was "just a tick box exercise" was often cited. GP practices in England operate a voluntary annual reward and incentive programme called Quality and Outcomes Framework (QOF). For some, ticking the box "asthma annual review" and answering 3 questions about the patient's asthma control is all that is needed to achieve QOF targets. One nurse commented "I thought QOF meant doing uniform asthma care but sadly that is not the case as there is different level of abilities doing them". Financial incentives exert an unclear effect on healthcare quality. ${ }^{13}$

Inertia was found to be another major barrier; driven by fear of what could happen after step down or concern about who is responsible for stepping down. In response to the UK's high asthma mortality rate, asthma charities and respiratory organisations have committed to the education of patients and professionals in the importance of adequately managing asthma, including patients with milder disease. $^{14,15}$ This is, without doubt, a vital, life-saving message. But perhaps a subtle consequence of this is a fear of attempting to reduce medication to reach its minimally effective dose. This has occurred in conjunction with an increasing choice, and fall in price, of combination inhalers often not available/licensed for low dose ICS use. In the UK, around two-thirds of asthma patients, that are managed with a preventer, use medium or high dose ICS. ${ }^{1}$ It is unclear whose role it is to step down, arguably it is everyone's role, but many doctors and some nurses did not feel it was their responsibility. This may be a major contributing factor, for example doctors often suggested it should be assessed 
during a nurse-led asthma review, whereas some nurses reported feeling hesitant to step-down medication prescribed by a doctor. Pharmacists reported high awareness of guidelines and management options, clinical pharmacists linked to GP practices could be a useful resource for safe and effective step-down practices.

Low self-efficacy is another key barrier. The lack of knowledge and skills to step down was reported by most participants, and exacerbated by a perceived lack of clear, practical guidance. Participants relied on guidelines to commence and step up medication, but felt they were lacking and vague for who, how and when to step down. All guidelines include a section on decreasing medication, but this is separated from the main stepwise approach pictogram. Study participants preferentially use BTS/SIGN and NICE guidelines which offer discretionary recommendations for step-down, to be directed by the professional and patient. This could be explained as step down potentially requires a more personalised approach, but it is more likely a consequence of the evidence gaps. Two Cochrane reviews found insufficient trial evidence regarding step down of ICS or long-acting beta agonists (LABA). ${ }^{16,17}$ Participants in our study used a variety of approaches to step down, reducing both ICS and LABA or just ICS; with even less concord for patients with an additional asthma therapy. Moreover, there was no consensus as to how to identify suitable patients.

Feasibility is a further significant factor affecting step down. Feasibility includes lack of time to step down effectively and safely, and lack of normalisation of the practice. Several participants suggested an acceptance of step down if it became a routine part of patient care, education and training. Interestingly, most participants were not aware of SMART or MART maintenance and reliever therapy regimens, ${ }^{2-4}$ or used them incorrectly, signifying a lack of knowledge in management options. These regimens already have behavioural elements relating to a step-down approach. Recently, trials have gone further and assessed the use of a combination inhaler in mild asthma solely as a symptom-driven regimen, as compared to a maintenance regimen. ${ }^{18,19}$ The perception of a subset of these patients was evaluated and found to be satisfied with either approach. ${ }^{20}$

These findings can be used by primary care practitioners, payers, asthma specialists, public health specialists and people with asthma to highlight the current barriers to stepping down asthma medication and therefore encourage commissioning of clearer asthma guidelines, undertake necessary evidence building and improve education and training around this topic.

\section{Strengths and Limitations}

By using a qualitative design this study has provided insights into a primary care professional's views, encounters, challenges and ideas around step down of asthma medication. Our participants represented a range of demography, experiences and professional roles from different tiers of the primary care landscape. In qualitative studies sample size is often considered enough when further interviews will not yield new responses. ${ }^{21} \mathrm{We}$ feel our data was adequate in this respect and complementary to recent UK observational data. ${ }^{1}$ However, it is possible there was some selection bias, such that those with an interest in asthma were more likely to participate. If this bias occurs, you may expect the health professionals that did not wish to participate were more likely to perceive the barriers we found. To try to circumnavigate this issue we selected participants for interview to include professionals with a mix of experience and interest; this was not possible with the survey. Of note, our study is exploratory and does not include the view of patients.

\section{Conclusion}

This study describes the current approach and perceptions of health practitioners to step down of asthma medication. Future directions should include (i) addressing gaps in current knowledge to build a robust evidence base, (ii) a change to guidelines, to show how to identify appropriate patients and provide clear definitions of operational aspects (incorporating shared decision making), (iii) integration of step-down assessment into routine asthma care and (iv) education and training of professionals and patients in step-down practice. Further study is required to investigate how training and education and incentivisation can be used to change current practice and attitudes regarding underused step-down practices.

\section{Acknowledgments}

We are grateful for the contribution of Vivienne Tickle and Samantha Jones, Asthma UK research and policy volunteers. We are grateful to the PMGUK admin team for allowing the survey to be posted on PMGUK and to the members that volunteered to do the survey and interviews from all over the UK. 


\section{Funding}

None received. The research was supported by the National Institute for Health Research (NIHR) Applied Research Collaboration (ARC) North West London. The views expressed are those of the authors and not necessarily those of the funder, the NHS, the NIHR or the Department of Health.

\section{Disclosure}

Dr Chloe I Bloom reports financial supports from Asthma UK, AstraZeneca, and Chiesi from outside the submitted work. Mrs Marsha Alter reports salaried from Community Pharmacy, Middlesex Group of LPC, NIHR, outside the submitted work. Mrs Shivali Lakhani reports salaried from Community Pharmacy, Middlesex Group of LPCs, NIHR, outside the submitted work. Dr Ernie Wong reports nonfinancial support from Chiesi Limited, personal fees from Astrazeneca UK, outside the submitted work. The authors report no other potential conflicts of interest for this work.

\section{References}

1. Bloom C, de Preux L, Sheikh A, Quint J, Kesselheim AS. Health and cost impact of stepping-down asthma medication for UK patients, 2001-2017: population-based observational study. PLoS Med. 2020;17(7):e1003145. doi:10.1371/journal.pmed.1003145

2. British Thoracic Society. BTS/SIGN British guideline on the management of asthma; 2019. Available from: file://C:/Users/sbloo/ Downloads/BTS_SIGN\%20Guideline $\% 20$ for $\% 20$ the $\% 20$ management \%20of\%20asthma\%202019\%20(4).pdf. Accessed September 8, 2020.

3. Global Initiative for Asthma. Global strategy for asthma management and prevention. 2020

4. National Instititute for Clinical Excellence. Asthma: diagnosis, monitoring and chronic asthma management. 2017. Available from: https:// www.nice.org.uk/guidance/ng80/resources/asthma-diagnosismonitoring-and-chronic-asthma-management-pdf-1837687975621. Accessed September 8, 2020.

5. Heffler E, Madeira LN, Ferrando M, et al. Inhaled corticosteroids safety and adverse effects in patients with asthma. J Allergy Clin Immunol Pract. 2018;6(3):776-781. doi:10.1016/j.jaip.2018.01.025

6. Health \& Social Care Information Centre. Prescription cost analysis England. 2012.
7. Averell CM, Stanford RH, Laliberté F, et al. Medication adherence in patients with asthma using once-daily versus twice-daily ICS/LABAs. J Asthma. 2019:1-10. doi:10.1080/02770903.2019.1663429

8. Bloom CI, Walker S, Quint JK. Inadequate specialist care referrals for high-risk asthma patients in the UK: an adult population-based cohort 2006-2017. J Asthma. 2019;1-7. doi:10.1080/02770903.2019.1672723

9. Reeve E, Wolff JL, Skehan M, et al. Assessment of attitudes toward deprescribing in older medicare beneficiaries in the United States. JAMA Intern Med. 2018;178(12):1673-1680. doi:10.1001/ jamainternmed.2018.4720

10. Chipps BE, Bacharier LB, Murphy KR, et al. Special series the asthma controller step-down yardstick. Ann Allergy Asthma Immunol. 2019;122(3):241-262. doi:10.1016/j.anai.2018.12.004

11. Rogers L, Reibman J. Stepping down asthma treatment: how and when. Curr Opin Pulm Med. 2012;18(1):70-75. doi:10.1097/ MCP.0b013e32834db017

12. Martin P, Tamblyn R, Benedetti A, Ahmed S, Tannenbaum C. Effect of a pharmacist-led educational intervention on inappropriate medication prescriptions in older adults: the D-PRESCRIBE randomized clinical trial. JAMA. 2018;320(18):1889-1898. doi:10.1001/jama.2018.16131

13. Mandavia R, Mehta N, Schilder A, Mossialos E. Effectiveness of UK provider financial incentives on quality of care: a systematic review. $\mathrm{Br}$ J Gen Pract. 2017;67(664):e800-e815. doi:10.3399/bjgp17X693149

14. Why asthma still kills: the National Review of Asthma Deaths (NRAD) Confidential Enquiry report. Royal College of Physicians. London; 2014. Available from: http://www.rcplondon.ac.uk/sites/ default/files/why-asthma-still-kills-full-report.pdf. Accessed September 12, 2020.

15. European Respiratory Society. Adult asthma. In: European Lung White Book. 2011. Available from: www.erswhitebook.org. Accessed September 12, 2020.

16. Ahmad S, Kew KM, Normansell R. Stopping long-acting beta 2 agonists (LABA) for adults with asthma well controlled by LABA and inhaled corticosteroids. Cochrane Database Syst Rev. 2015; CD011306.

17. Crossingham I, Evans DJ, Halcovitch NR, Marsden PA. Stepping down the dose of inhaled corticosteroids for adults with asthma. Cochrane Database Syst Rev. 2017. doi:10.1002/14651858. CD011802.pub2

18. Bateman ED, Reddel HK, O’Byrne PM, et al. As-needed budesonideformoterol versus maintenance budesonide in mild asthma. $N$ Engl J Med. 2018;378(20):1877-1887. doi:10.1056/NEJMoa1715275

19. O'Byrne PM, FitzGerald JM, Bateman ED, et al. Inhaled combined budesonide-formoterol as needed in mild asthma. $N$ Engl $J$ Med. 2018;378(20):1865-1876. doi:10.1056/NEJMoa1715274

20. Baggott C, Reddel HK, Hardy J, et al. Patient preferences for symptomdriven or regular preventer treatment in mild to moderate asthma findings from the PRACTICAL study, a randomised clinical trial. Eur Respir J. 2020;55(4):1902073. doi:10.1183/13993003.02073-2019

21. Moser A, Korstjens I. Series: practical guidance to qualitative research. Part 3: sampling, data collection and analysis. Eur J Gen Pract. 2018;24(1):9-18. doi:10.1080/13814788.2017.1375091

\section{Publish your work in this journal}

The Journal of Asthma and Allergy is an international, peer-reviewed open-access journal publishing original research, reports, editorials and commentaries on the following topics: Asthma; Pulmonary physiology; Asthma related clinical health; Clinical immunology and the immunological basis of disease; Pharmacological interventions and

Submit your manuscript here: https://www.dovepress.com/journal-of-asthma-and-allergy-journal new therapies. The manuscript management system is completely online and includes a very quick and fair peer-review system, which is all easy to use. Visit http://www.dovepress.com/testimonials.php to read real quotes from published authors. 